\title{
Do We Need To Evaluate Patients With Spontaneous Subconjunctival Hemorrhage For Bleeding Disorders?
}

\author{
Selim Sayın ${ }^{1}$ and Arif Ülkü Yener ${ }^{2}$ \\ ${ }^{1}$ Ankara Gülhane Eğitim ve Araştırma Hastanesi \\ ${ }^{2}$ Ankara Keçiören Eğitim ve Araştırma Hastanesi
}

October 4, 2021

\begin{abstract}
Aim of the study: Subconjunctival hemorrage $(\mathrm{SCH})$ is a frequent bleeding manifestation and a common cause of visits to the primary care. Trauma in young patients and vascular damage such as hypertension in the elderly are the most common causes of SCH and the prevalence of hematological diseases is less than $1 \%$. We aimed to evaluate the prevalence of congenital or acquired bleeding disorders in patients with once or recurrent SCH. Methods used to conduct the study: It is a retrospective study and included fifty-two patients with $\mathrm{SCH}$ whose etiologic factor was not detected. Hemostatic tests were studied in 52 patients (25 male and 27 females). All patients included were evaluated for congenital or acquired bleeding disorder and SCH with once and those with 2 or more were compared for the laboratory results. Results of the study: Type I von Willebrand disease (vWD) was diagnosed in one patient with recurrent SCH and one patient with single SCH (3.8\%). The prevalence of patients with type $1 \mathrm{vWD}$ in the study was not statistically significant when compared with the frequency of vWD in the normal population. Fibrinogen level was found to be statistically higher in patients who had SCH once than those who had recurrent $\mathrm{SCH}$. But fibrinogen level was in normal range in all patients. Conclusions drawn from the study and clinical implications: There was no increase in the incidence of congenital or acquired bleeding disorder in SCH compared to normal population. For this reason it was thought that there was no need for evaluation for bleeding disorders in spontaneous $\mathrm{SCH}$.
\end{abstract}

\section{Do We Need To Evaluate Patients With Spontaneous Subconjunctival Hemorrhage}

\section{For Bleeding Disorders?}

\section{Abstract}

Aim of the study: Subconjunctival hemorrage $(\mathrm{SCH})$ is a frequent bleeding manifestation and a common cause of visits to the primary care. Trauma in young patients and vascular damage such as hypertension in the elderly are the most common causes of SCH and the prevalence of hematological diseases is less than $1 \%$.

We aimed to evaluate the prevalence of congenital or acquired bleeding disorders in patients with once or recurrent $\mathrm{SCH}$.

Methods used to conduct the study: It is a retrospective study and included fifty-two patients with $\mathrm{SCH}$ whose etiologic factor was not detected. Hemostatic tests were studied in 52 patients (25 male and 27 females). All patients included were evaluated for congenital or acquired bleeding disorder and SCH with once and those with 2 or more were compared for the laboratory results.

Results of the study: Type I von Willebrand disease (vWD) was diagnosed in one patient with recurrent $\mathrm{SCH}$ and one patient with single SCH (3.8\%). The prevalence of patients with type $1 \mathrm{vWD}$ in the study was not statistically significant when compared with the frequency of vWD in the normal population. Fibrinogen 
level was found to be statistically higher in patients who had SCH once than those who had recurrent SCH. But fibrinogen level was in normal range in all patients.

Conclusions drawn from the study and clinical implications: There was no increase in the incidence of congenital or acquired bleeding disorder in $\mathrm{SCH}$ compared to normal population. For this reason it was thought that there was no need for evaluation for bleeding disorders in spontaneous SCH.

Keywords: bleeding disorder, screening, subconjunctival hemorrhage, von Willebrand disease

\section{What' known?}

The first referral center of patients with spontaneous subconjunctival hemorrhage is usually family medicine and the correct management of these patient is very important. Bleeding disorders are frequently reported to play a role in the etiology of $\mathrm{SCH}$, but few studies have investigated the prevalence and clinical significance. The most important question to be answered in these patients is who should we screen for bleeding disorders or should we refer tertiary centers?

\section{What' new?}

In this study patients who were not found to have an etiological factor such as trauma, eye infection, hypertension, diabetes and drugs, that would cause $\mathrm{SCH}$ were evaluated for bleeding disorder. We also firstly evaluated for congenital or acquired bleeding disorder and spontaneous subconjunctival hemorrhage with once and those with two or more. We found no increased incidence of congenital or acquired bleeding disorders in $\mathrm{SCH}$ patients compared to the normal population. In terms of bleeding history in two patients with vWD, they reported more bleeding findings in other patients. It was concluded that only SCH patients with a history of other systemic bleeding such as recurrent epistaxis, skin and mucosal, minor post-traumatic bleeding, hematuria, gastrointestinal bleeding, tooth extraction, post-operative bleeding, hemarthrosis, menorrhagia should be screened for congenital bleeding disorder.

\section{Introduction}

Subconjunctival hemorrhage ( $\mathrm{SCH})$ is acute bleeding with sharp borders underneath the conjunctiva. It is often a cause of concern in patients and is therefore one of the most common reasons for referral to ophthalmology clinics from primary care ${ }_{[1,2]}$. It is usually unilateral and the region and size of the bleeding vary according to the etiology. Fukuyama et al reported the incidence of $\mathrm{SCH}$ as $2.9 \%_{[3]}$. Although the most common cause for $\mathrm{SCH}$ is trauma and contact lens-induced injury in younger patients, among older patients it is mostly associated with hypertension, diabetes mellitus and anticoagulant usage ${ }_{[4,5]}$. Despite all these reasons, the cause of most cases remains unexplained. Bleeding disorders are frequently reported to play a role in the etiology of $\mathrm{SCH}$, but few studies have investigated the prevalence and clinical significance ${ }_{[3]}$. In addition to anticoagulant and antiaggregant usage, immune thrombocytopenia and congenital bleeding disorders have been reported in a few studies as hemostatic alterations at the etiology of SCH $[6-9]$.

The aim of this study was to evaluate the prevalence of congenital or acquired bleeding disorders in patients with once or recurrent $\mathrm{SCH}$ and to investigate the clinical characteristics of patients with $\mathrm{SCH}$ presenting to Ophthalmology Division.

\section{Methods}

In this retrospective study, the patients admitted to Ophthalmology and Hematology Division were enrolled between February 1, 2018, and November 30, 2019. The patients who admitted to the ophthalmology outpatient clinic due to once or recurrent $\mathrm{SCH}$, underwent a complete ophthalmologic examination, including the best corrected visual acuity level, slit-lamp biomicroscopy, intraocular pressure measurement with Goldmann applanation tonometer and dilated fundoscopy. Patients who didn't have any etiological reasons for bleeding such as conjunctivitis, episcleritis, keratitis, corneal ulcer, glaucoma, dry eye and blepharitis, were referred to the hematology outpatient clinic for evaluation of bleeding disorders. 
All patients were questioned for ocular trauma (including the usage of lenses), systemic hypertension, diabetes, cardiovascular abnormalities, fever and medications affecting platelet function or blood clotting, such as nonsteroidal anti-inflammatory drugs, aspirin, antiplatelet agents, heparin, oral anticoagulants, antivitamin $\mathrm{K}$ or non-vitamin $\mathrm{K}$ oral anticoagulants (NOACs), steroids, antiepileptics or antidepressants and if any, they were excluded from the study. Patients' bleeding histories were also evaluated using a standardized bleeding assessment tool (BAT) created by International Society on Thrombosis and Hemostasis (ISTH).

Complete blood count (CBC), prothrombin time (PT), activated partial thromboplastin time (aPTT), fib-

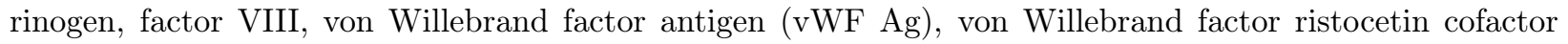
(vWF Rco) and factor XIII antigen levels were tested from all patients meeting inclusion criterias. PFA-100 (collagen / epinephrine (C / Epi), collagen / ADP (C / ADP) and closure time (CT) were studied in available patients. Thrombin time was studied in a small number of patients. According to these laboratory results, the patients with the hemorrhagic disorders were determined and SCH with once and those with 2 or more were compared for the laboratory results.

Statistical Package for the Social Sciences (SPSS) version 15.0 was used for the analysis. The distribution of the datas were assessed using a one-sample Kolmogorov-Smirnov test. Normally distributed continuous variables were expressed as the mean $\pm \mathrm{SD}$, skew-distributed continuous variables were expressed as the median (minimum-maximum), and categorical variables were expressed as the number and percentage. For comparison of categorical variables, Fisher's exact test or a chi-square test was used. Differences between numeric variables were tested with Student's t-test or a Mann-Whitney U-test, where appropriate. A p-value of less than 0.05 was considered as statistically significant.

All procedures performed in studies involving human participants were in accordance with the ethical standards of the institutional and/or national research committee and with the 1964 Helsinki declaration and its later amendments or comparable ethical standards. (Kecioren Educational and Research Hospital08.01.2020/2027)

\section{Results}

A total of $52 \mathrm{SCH}$ patients were included in the study. Mean age of the patients was $50.86 \pm 13.11$ years (18-75). 25 were male and 27 were females. 35 patients have once SCH and 17 patients have more than two (Table 1). The mean and standard deviation of laboratory results of all patients, and patients who have $\mathrm{SCH}$ once and two or more were given at the table 2. One patient with once and one patient with recurrent SCH $(3.8 \%)$ were diagnosed a type I vWD (table 3 ). The prevalence of type $1 \mathrm{vWD}$ in the study was not statistically significant when compared with the frequency of vWD in the Turkish population.

Fibrinogen level was found to be statistically higher in patients who had SCH once than those who had recurrent $\mathrm{SCH}(\mathrm{p}=0.048)$. But fibrinogen level was in normal range in all patients. Thrombin time was studied in a small number of patients and all results were in normal range. Dysfibrinogenemia was not considered clinically in any patient.

There were 12 patients who reported a previous history of bleeding. The most frequently reported symptoms, in order of frequency, are recurrent skin and mucosal bleeding, minor post-traumatic bleeding, menorrhagia and recurrent epistaxis.

\section{Discussion}

The first presentation of patients with SCH is usually to the family medicine and there are few studies on whether these patients should be evaluated for bleeding disorder. $\mathrm{SCH}$ is a mucosal hemorrhage and is expected in the qualitative deficiency of platelets or in platelet function disorders and coagulation factor deficiencies. In most of the non-traumatic SCH cases, the etiological causes are hypertension, diabetes mellitus and drugs. In addition, coagulation factor deficiency was detected in less than $1 \%$ of patients (10). During anticoagulant and antiaggregant usage, and hemostatic alterations as immune thrombocytopenia, congenital bleeding disorders and hematologic malignancy as leukemia, SCH was reported in previous cases $[3,9-11]$. 
However, in these cases $\mathrm{SCH}$ is considered to be a part of other mucocutaneous bleeding, and patients often apply to the hematology outpatient clinic.

Hypertension, diabetes mellitus and other systemic vascular disorders play a major role in the etiology of subconjunctival hemorrhage and their prevalence increases with age. Because of this, the number of patients with SCH increases markedly over 50 years of age $e_{[12,13]}$. Although only spontaneous SCH were included in our study, the mean age of patients was found to be over 50 years as in previous studies. The frequency of non-traumatic SCH was reported to be more common in women in previous studies ${ }_{[4,6]}$. In our study, although SCH was seen more frequently in women, it was found to be close in frequency to each other in both sexes. In $32.7 \%$ of cases, spontaneous SCH was recurrent in the absence of any identifiable causes or risk factors. This rate was higher than some previous studies ${ }_{[7]}$. Lens usage is an exclusion criteria in our study since it may lead to traumatic SCH. Although the usage of glasses was not considered to be a risk factor for $\mathrm{SCH}$, it was determined that approximately one third of the cases were wearing glasses. The incidence of $\mathrm{SCH}$ is similar in both eyes.

In our country patients pay attention to the SCH rather than cutaneous bleeding. Therefore, patients may consult a doctor when they first underwent SCH despite previous recurrent other mucocutaneous bleeding. From this point we thought that the first finding of congenital bleeding disorders such as vWD may be $\mathrm{SCH}$ and we expected increased frequency of congenital or acquired bleeding disorders in patients with spontaneous SCH. However we showed that the prevalence of hemostatic alterations in patients with once or recurrent, spontaneous $\mathrm{SCH}$ is not different from that in the general population. There was also no difference between coagulation factor levels and hemostasis tests between those who had once SCH and recurrent SCH.

In few studies, no difference was found in platelet count or coagulation factor levels in recurrent $\mathrm{SCH}$ patients from that in the general population as in our study $[6,7,10]$. Although few studies have shown that homozygosity and heterozygosity for the Val 34Leu mutation of blood clotting factor FXIII is more frequent detected in SCH cases, factor XIII antigen levels were within the normal limits in all patients in our study $[8,14]$. Likewise in a study, there were no correlation between factor XIII antigen/activity levels and $\mathrm{SCH}_{[6]}$.

$40(76.9 \%)$ of the patients included in our study had a ISTH-BAT score of 0 and no bleeding disorder was detected. When the other bleeding findings of 2 patients with type $1 \mathrm{vWD}$ were evaluated, it was learned that they had bleeding attacks as epistaxis, cutaneous bleeding, menorrhagia, bleeding after tooth extraction and bleeding from minor wounds. The ISTH-BAT score of these two cases was 3 and 4, respectively. Although there seems to be a strong relationship between ISTH-BAT scores and vWD, there is no statistcal sample size to demonstrate this in our study. The necessity of evaluating patients with spontaneous SCH for bleeding disorder is stil a confusing. Although few studies suggest that spontaneous SCH should be evaluated for bleeding disorder, the conclusion to be drawn from our study is that, it is a more accurate approach to investigate bleeding disorder only in $\mathrm{SCH}$ patients with a history of bleeding ${ }_{[1,5]}$. It is also more cost effective.

In addition, fibrinogen level was the only statistically significant parameter in the comparison between patients with once SCH and recurrent SCH and it was lower in patients with recurrent SCH. Thrombin time was studied in five patients and all results were in normal range. Although it was statistically significant, fibrinogen levels in all patients were within normal limits and it was considered to have no clinical significance. Dysfibrinogenemia was also not considered clinically in any patient.

The first limitation of our study was the fact that the PFA-100 test was performed by appointment, and therefore the PFA-100 test could be performed at 2-3 weeks after subconjunctival hemorrhage in all patients. The second, although factor XIII antigen levels were studied in all patients, none of them had laboratory examination of factor XIII activity and Light transmission aggregometry. However, according to the data from previous studies, it is considered that this situation has no effect on the results of our study.

Patients presenting with SCH should be questioned and examined in details for common etiological risk factors such as hypertension, diabetes mellitus, fever, trauma, drug use, conjunctivitis, blepharitis, episcleritis, 
and corneal ulcer. If diseases such as dry eye or glaucoma are suspected, the patient should be referred to an ophthalmologist for eye examination.

In addition, in terms of other systemic bleeding findings such as recurrent epistaxis, skin and mucosal, minor post-traumatic bleeding, hematuria, gastrointestinal system bleeding, tooth extraction, post-surgical bleeding, hemarthrosis, menorrhagia, intramuscular, postpartum and central nervous system bleeding should be questioned. It should be known that acutely developing hematological diseases such as leukemias and thrombocytopenia may rarely present with $\mathrm{SCH}$ as a single mucosal site. It should be kept in mind that it is often associated with skin and other system bleeding. In congenital bleeding disorders, patients often have a history of previous skin and mucosal bleeding, and a history of prolonged bleeding after surgical procedures. Patients with a history of bleeding should be referred to a hematologist. However, it should be known that less than $1 \%$ of SCH patients will develop due to hematological reasons.

In conclusion, we suggest not to examine patients with spontaneous SCH for bleeding disorder, according to the data obtained from our study. Patients with spontaneous SCH should be evaluated with ISTH-BAT score instead of directly laboratory examination for bleeding disorder and evaluation for the congenital bleeding disorders of patients with other bleeding histories and high bleeding score would be more accurate.

\section{Declaration}

No funding and financial support was received for this submission.

The authors declare that they have no conflict of interest.

All the datas and materials are available for checking.

\section{References}

1. Cronau H, Kankanala RR, Mauger T. (2010) Diagnosis and management of red eye in primary care. Am Fam Physician 81:137-144.

2. Tarlan B, Kiratli H. (2013) Subconjunctival hemorrhage: risk factors and potential indicators. Clin Ophthalmol 7:1163-1170. doi: 10.2147/OPTH.S35062

3. Fukuyama J, Hayasaka S, Yamada K et al. (1990) Causes of subconjunctival hemorrhage. Ophthalmologica 200:63-67. doi: 10.1159/000310079

4. Mimura T, Yamagami S, Usui T et al. (2010) Location and extent of subconjunctival hemorrhage. Ophthalmologica. 224(2):90-95. doi: 10.1159/000235798

5. Sahinoglu-Keskek N, Cevher S, Ergin A. (2013) Analysis of subconjunctival hemorrhage. Pak J Med Sci. 29:132-134. doi: 10.12669/pjms.291.2802

6. Fierro T, Bartolini A, Mezzasoma AM et al. (2016) Prevalence of hemostatic alterations in patients with recurrent spontaneous subconjunctival hemorrhage. Clin Chem Lab Med.97-103. doi: 10.1515/cclm2015-0274

7. Cagini C, Iannone A, Bartolini A et al. (2016) Reasons for visits to an emergency center and hemostatic alterations in patients with recurrent spontaneous subconjunctival hemorrhage. Eur J Ophthalmol 26 (2):188-192. doi: 10.5301/ejo.5000692

8. Incorvaia C, Costagliola C, Parmeggiani F et al. (2002) Recurrent episodes of spontaneous subconjunctival hemorrhage in patients with factor XIII Val34Leu mutation. Am J Ophthalmol. 134:927-929. doi : 10.1016/s0002-9394(02)01812-3

9. Sodhi PK, Jose R. (2003) Subconjunctival hemorrhage: the first presenting clinical feature of idiopathic thrombocytopenic purpura. Jpn J Ophthalmol. 47: 316-318. doi :10.1016/s0021-5155(03)00017-0

10. Hu DN, Mou CH, Chao SC et al. (2015) Incidence of Non-Traumatic Subconjunctival Hemorrhage in a Nationwide Study in Taiwan from 2000 to 2011. Plos One 10(7) 1-10. doi: 10.1371/journal.pone.0132762

11. Taamallah-Malek I, Chebbi A, Bouladi M et al. (2013) Massive bilateral subconjunctival hemorrhage revealing acute lymphoblastic leukemia. J Fr Ophtalmol 36:45-48. doi: 10.1016/j.jfo.2012.03.013

12. Wilson RJ. (1986) Subconjunctival hemorrhage: overview and management. J Am Optom Assoc. $57: 376-380$. 
13. Mimura T, Usui T, Yamagami S et al. (2010) Recent causes of subconjunctival hemorrhage. Ophthalmologica 224(3):133-137. doi: 10.1159/000236038

14. Parmeggiani F, Costagliola C, Incorvaia C et al. (2004) Prevalence of factor XIII Val34Leu polymorphism in patients affected by spontaneous subconjunctival hemorrhage. Am J Ophthalmol 138:481-484. doi: $10.1016 /$ j.ajo.2004.03.017

Table 1: Characteristics of the patient with subconjunctival hemorrhage

\begin{tabular}{ll}
\hline Variables & \\
Age (years) & $50.8 \pm 13.1$ \\
Sex & Male \\
Female & $27(52 \%)$ \\
Glasses usage & Yes \\
No & $33(63.5 \%)$ \\
Frequency of SCH & $\mathbf{1}$ \\
{$[?] \mathbf{2}$} & $17(32.7 \%)$ \\
Eye involvement & Right eye \\
Left eye & $27(51.9 \%)$ \\
ISTH-BAT score & $\mathbf{0}$ \\
$\mathbf{1}$ & $5(9.6 \%)$ \\
$\mathbf{2}$ & $4(7.7 \%)$ \\
{$[?] \mathbf{3}$} & $3(5.8 \%)$ \\
\hline
\end{tabular}

Abbreviation: $\mathrm{SCH}=$ subconjunctival hemorrage, ISTH-BAT $=$ bleeding assessment tool created by International Society on Thrombosis and Hemostasis.

Table 2: The mean and standard deviation of laboratory results

\begin{tabular}{|c|c|c|c|c|c|}
\hline $\begin{array}{l}\text { Laboratory } \\
\text { Test } \\
\text { (Normal } \\
\text { Range) } \\
\end{array}$ & $\begin{array}{l}\text { Laboratory } \\
\text { Test } \\
\text { (Normal } \\
\text { Range) } \\
\end{array}$ & Mean \pm SD & Mean \pm SD & Mean \pm SD & \\
\hline & & All cases & $\begin{array}{l}\text { Frequency of } \\
\mathrm{SCH}=1\end{array}$ & $\begin{array}{l}\text { Frequency of } \\
\mathrm{SCH}=[?] 2\end{array}$ & $\mathbf{P}$ value \\
\hline $\begin{array}{l}\text { Platelet } \\
\left(/ \mathrm{mm}^{3}\right) \\
(150000- \\
450000)\end{array}$ & $\begin{array}{l}\text { Platelet } \\
\left(/ \mathrm{mm}^{3}\right) \\
(150000- \\
450000)\end{array}$ & $\begin{array}{l}241326.92 \\
( \pm 49384.33)\end{array}$ & $\begin{array}{l}238000 \\
( \pm 50048.21)\end{array}$ & $\begin{array}{l}248176 \\
( \pm 48753.50)\end{array}$ & $>0.05$ \\
\hline $\begin{array}{l}\text { PT (sec) } \\
(10-15)\end{array}$ & $\begin{array}{l}\text { PT (sec) } \\
(10-15)\end{array}$ & $11.29( \pm 0.91)$ & $11.44( \pm 0.94)$ & $10.98( \pm 0.79)$ & $>0.05$ \\
\hline INR & INR & $0.97( \pm 0.07)$ & $0.99( \pm 0.07)$ & $0.94( \pm 0.04)$ & $>0.05$ \\
\hline $\begin{array}{l}\text { aPTT (sec) } \\
(22.1-38)\end{array}$ & $\begin{array}{l}\text { aPTT (sec) } \\
(22.1-38)\end{array}$ & $25.77( \pm 2.45)$ & $26.07( \pm 2.24)$ & $25.77( \pm 3.59)$ & $>0.05$ \\
\hline $\begin{array}{l}\text { Fibrinogen } \\
(\mathrm{mg} / \mathrm{dL}) \\
(180-350)\end{array}$ & $\begin{array}{l}\text { Fibrinogen } \\
(\mathrm{mg} / \mathrm{dL}) \\
(180-350)\end{array}$ & $\begin{array}{l}273.80 \\
( \pm 68.72)\end{array}$ & $\begin{array}{l}285.50 \\
( \pm 73.71)\end{array}$ & $\begin{array}{l}250.42 \\
( \pm 51.77)\end{array}$ & $<0.05$ \\
\hline $\begin{array}{l}\text { Factor VIII } \\
\text { Level (\%) } \\
(50-120)\end{array}$ & $\begin{array}{l}\text { Factor VIII } \\
\text { Level (\%) } \\
(50-120)\end{array}$ & $82.53( \pm 29.92)$ & $82.74( \pm 31.54)$ & $82.11( \pm 27.21)$ & $>0.05$ \\
\hline
\end{tabular}




\begin{tabular}{|c|c|c|c|c|c|}
\hline $\begin{array}{l}\text { Laboratory } \\
\text { Test } \\
\text { (Normal } \\
\text { Range) }\end{array}$ & $\begin{array}{l}\text { Laboratory } \\
\text { Test } \\
\text { (Normal } \\
\text { Range) }\end{array}$ & Mean $\pm \mathrm{SD}$ & Mean $\pm \mathrm{SD}$ & Mean $\pm \mathrm{SD}$ & \\
\hline $\begin{array}{l}\text { Factor XIII } \\
\text { Level (\%) } \\
(60-192)\end{array}$ & $\begin{array}{l}\text { Factor XIII } \\
\text { Level (\%) } \\
(60-192)\end{array}$ & $94.78( \pm 32.68)$ & $94.22( \pm 33.77)$ & $95.94( \pm 31.30)$ & $>0.05$ \\
\hline \multirow[t]{2}{*}{ vWF Ag (\%) } & $\begin{array}{l}\text { AB Group } \\
(47-197)\end{array}$ & $91.80( \pm 34.20)$ & $90.80( \pm 36.42)$ & $94.09( \pm 30.02)$ & $>0.05$ \\
\hline & $\begin{array}{l}\text { O Group } \\
(30-197)\end{array}$ & $65.81( \pm 13.60)$ & $67.50( \pm 9.67)$ & $63.00( \pm 19.26)$ & $>0.05$ \\
\hline \multirow[t]{2}{*}{$\begin{array}{l}\text { vWF Rco } \\
(\%)\end{array}$} & $\begin{array}{l}\text { AB Group } \\
(51-215)\end{array}$ & $94.63( \pm 36.76)$ & $96.80( \pm 39.27)$ & $89.72( \pm 31.46)$ & $>0.05$ \\
\hline & $\begin{array}{l}\text { O Group } \\
(30-215)\end{array}$ & $66.62( \pm 23.29)$ & $75.20( \pm 20.77)$ & $52.33( \pm 21.43)$ & $>0.05$ \\
\hline \multirow[t]{3}{*}{ PFA-100 } & $\begin{array}{l}\text { C/Epi (\%) } \\
(>60)\end{array}$ & $97.05( \pm 23.09)$ & $\begin{array}{l}103.87 \\
( \pm 14.87)\end{array}$ & $93,87( \pm 25.91)$ & $>0.05$ \\
\hline & $\begin{array}{l}\text { C/ADP (\%) } \\
(>60)\end{array}$ & $86.01( \pm 9.50)$ & $86.38( \pm 10.72)$ & $85.87( \pm 9.37)$ & $>0.05$ \\
\hline & $\begin{array}{l}\text { CT (sec) } \\
(0-60)\end{array}$ & $13.76( \pm 14.62)$ & $16.4( \pm 14.53)$ & $13.04( \pm 15.26)$ & $>0.05$ \\
\hline
\end{tabular}

Abbreviation: $\mathrm{PT}=$ prothrombin time, aPTT=activated partial thromboplastin time, vWF $\mathrm{Ag}=$ von Willebrand factor antigen, $\mathrm{vWF}$ Rco=von Willebrand factor ristocetin cofactor, PFA-100 C/Epi= collagen/epinephrine, $\mathrm{C} / \mathrm{ADP}=$ collagen/ADP, $\mathrm{CT}=$ closure time.

Table 3: Characteristics of two cases with vWD.

\begin{tabular}{lll}
\hline & Case-1 & Case-2 \\
\hline Gender & Female & Male \\
Age & 49 & 65 \\
Frequency of SCH & 2 & 1 \\
ISTH-BAT score & 4 & 3 \\
Platelet (/. mm ${ }^{3}$ ) & 282000 & 237000 \\
Blood group & O Rh $(+)$ & $\mathrm{B} \mathrm{Rh}(+)$ \\
aPTT (sec) & 34.5 & 27.9 \\
Factor VIII Level (\%) & 49 & 45 \\
vWF Ag (\%) & 28 & 41 \\
vWF Rco (\%) & 16 & 44 \\
\hline
\end{tabular}

Abbreviation: $\mathrm{SCH}=$ subconjunctival hemorrage, ISTH-BAT = bleeding assessment tool created by International Society on Thrombosis and Hemostasis, aPTT=activated partial thromboplastin time, $\mathrm{vWF} \mathrm{Ag=von}$ Willebrand factor antigen, $\mathrm{vWF}$ Rco=von Willebrand factor ristocetin cofactor, 